\title{
PENGARUH HARGA DAN MODEL TERHADAP KEPUASAN KONSUMEN KAOS SABLON DI KAWASAN MALIOBORO YOGYAKARTA
}

\author{
Wendri Rusli \\ Universitas Cokroaminoto Yogyakarta
}

\begin{abstract}
.
This research aimed to prove that consumer satisfaction to singlet that is on the market at Malioboro Yogyakarta's area regarded by factor price and model. At deep observational being done to 100 respondents have already buy and have once had templet singlets. Utilizing computer with SPSS 13.0 for is windows o analisis by uses bifilar linear regression to be gotten price result and positive ascendant model and signifikan to consumer decision. Done by quiz t and quiz $f$ signifikan's ala and unsure's positive price and model regards consumer decision. Be of yielding beta coefficient quiz gotten by factor decision dominant buys to be regarded by model.
\end{abstract}

Keywords: satisfaction, price, model, bifilar linear regression

\section{PENDAHULUAN}

Yogyakarta sebagai pusat pemerintahan politik baru secara resmi berdiri sejak Pangeran Mangkubumi (Sultan Hamengku Buwono I) mengakhiri pemberontakan yang dipimpinnya, mendapat wilayah kekuasaan separuh wilayah Mataram yang tersisa, dan diizinkan mendirikan keraton di tempat yang dikenal sekarang. Tanggal wisuda keraton ini, 7 Oktober 1756, kini dijadikan sebagai hari jadi kota Yogyakarta.

Menurut Supantono, Widihardjo, dan Haldani (2006) karakteristik dari masyarakat Yogyakarta adalah nilai-nilai luhur yang telah tertanam sejak lama dalam setiap aspek kehidupan masyarakat. Berikut ini merupakan kristalisasi nilai-nilai luhur yang menjadi pondasi utama dalam kehidupan masyarakat Yogyakarta. Pertama: iman dan taqwa, yaitu aspek spiritual yang menjadi ciri masyarakat Yogyakarta. Aspek ini membuat kota Yogyakarta mendapat sebutan kota pendidikan dan pariwisata. Kedua: kreatif dan inovatif, yaitu sifat khas masyarakat Yogyakarta yang memiliki jiwa kewirausahaan (entrepreuneurship) dalam memanfaatkan setiap potensi yang ada, mencoba ide baru dan mencari solusi baru atas hambatan dan tantangan yang dihadapi. Aspek inilah yang mendorong pertumbuhan berbagai jenis industri kecil dan aneka kerajinan termasuk salah satunya adalah kaos sablon. Ketiga: kooperatif dan kompetitif, artinya dalam lingkungan sosial, budaya dan ekonomi masyarakat Yogyakarta memegang teguh nilai kebersamaan dan kekeluargaan dalam menjalankan roda perekonomian, ulet dan tangguh dalam menghadapi persaingan. Gotong royong merupakan implementasi dari nilai tersebut dalam lingkungan sosial. Keempat: amanah, yaitu merupakan sifat akuntabilitas dari masyarakat Yogyakarta, artinya masyarakat yang jujur.

Yogyakarta dikenal sebagai kota pelajar, karena hampir $20 \%$ penduduk produktifnya adalah pelajar dan terdapat 137 perguruan 
tinggi. Kota ini diwarnai dinamika pelajar dan mahasiswa yang berasal dari berbagai daerah di Indonesia. Kaos sablon sebagai hasil dari budaya yang dikembangkan oleh masyarakat Yogyakarta merupakan komoditas andalan bagi pemerintah daerah dan pusat sebagai penopang devisa negara. Proses pembuatan dilakukan di tempat dengan sifat home industries menggunakan mesin digital dan offset, menggunakan bahan dan biaya yang relatif murah, serta pembentukan desain yang berkelanjutan dengan inovasi atau creative. Pola pikir dan aktivitas usaha berlandaskan kepada tiga filosofi, yaitu: (1) merupakan produk lokal yang mengglobal, (2) menghasilkan produk atas kreativitas dan dengan kemampuan sendiri, serta (3) sekaligus mengembangkan kemampuan sumber daya manusia.

Menurut Simatupang (2008), pemerintah Indonesia melalui Departemen Perdagangan dan Industri telah memetakan 14 sektor industri kreatif yaitu: barang seni dan barang antik, arsitektur, periklanan, kerajinan, desain, pakaian, seni pertunjukan, televisi dan radio, fotografi dan film, interaktif, musik, komputer, penerbitan dan percetakan, serta penelitian dan pengembangan. Bagi negara Indonesia ekonomi kreatif memberi konstribusi bagi Produk Domestik Bruto 4,8\% untuk tahun 2006 dan 7\% untuk nilai ekspor tahun 2006. Tingkat pertumbuhan sebesar 7,3\% sedangkan pertumbuhan ekonomi secara nasional $5,60 \%$ dan penyerapan tenaga kerja 3,7 juta setara dengan $4,7 \%$ dari total. Kemampuan produk seni dan kerajinan menyerap 18,30\%.

Kawasan Malioboro Yogyakarta sebagai area nyaman tujuan wisata sebagai wilayah nostalgia dan bersejarah dengan romantika kehidupan bernuansa budaya. Saat ini dan masa yang akan datang kawasan ini sebagai pasar yang potensial untuk pengembangan usaha kaos sablon. Wendri (2012) menyatakan bahwa model mempengaruhi pembeli wisatawan di Yogyakarta. Perkembangan industri restoran hingga saat ini masih diyakini sebagai salah satu bentuk usaha ekonomi yang memiliki prospek yang cukup baik. Kompetisi untuk meningkatkan keuntungan (rate of return) diperoleh pengelola kaos sablon mengarah di keseimbangan. Agar dapat bersaing, perlu pembenahan agar mampu beradaptasi secara tepat terhadap peluang. Beberapa masalah mengenai kualitas model memberikan dampak negatif terhadap keberlangsungannya. Pelanggan merasa kurang puas karena model dan corak kaos sablon belum baik. Pelanggan cenderung akan mencari dan berupaya menemukan barang lain sebagai pengganti.

Berdasarkan fenomena tersebut, keberhasilan usaha kaos sablon di Kotamadya Yogyakarta memakai strategi Miles dan Snow. Menurut Polyorat (2010), fungsi operatif dalam perencanaan sumber daya manusia, rekrutmen, pemberian kompensasi, motivasi, komunikasi, pelatihan dan pelaksanaan pemutusan hubungan kerja. Menurut Firmansyah (2010), usaha kecil dikelola secara kekeluargaan dan menggunakan teknologi yang masih tradisional. Pemilik sebagian besar memiliki pendidikan yang tidak tinggi namun dapat menjadikan perusahaan berhasil mencapai kesuksesan. Peneliti memilih usaha kaos sablon sebagai objek penelitian. Usaha kaos sablon Victor yang juga menghadapi persaingan, perlu memperhatikan dan menjaga kualitas layanan untuk memberikan kepuasan untuk menjaga loyalitas konsumen terhadap usaha kaos sablon di kota Yogyakarta. Keberadaan usaha kaos sablon merupakan peluang usaha yang menguntungkan.

Hasil wawancara dengan pemilik usaha kaos sablon, masalah yang dihadapi dalam upaya memberikan layanan untuk menciptakan kepuasan dan loyalitas pelanggan antara lain perlu adanya perhatian atas beberapa fasilitas fisik untuk menciptakan daya tarik dan menciptakan kenyamanan bagi pelanggan, serta kurangnya varian kaos sablon pada saat memberikan layanan kepada konsumen. Menurut Florida (2002), kepemilikan suatu keahlian yang unik 
untuk bidang inovasi dan produksi non material merupakan modal dasar. Peranan edukasi kepada para pelaku usaha kaos sablon diperlukan untuk menciptakan daya tarik dan menciptakan kenyamanan bagi pelanggan serta kreativitas untuk membentuk opini kaos sablon dipandang menarik.

\section{REVIEW LITERATUR DAN HIPOTESIS}

Sejak pemerintah mencanangkan kekuatan ekonomi kreatif, kegiatan usaha sablon di Yogyakarta mengalami perkembangan yang positif dan signifikan dengan semakin meningkatnya kunjungan wisata baik dari dalam maupun luar negeri. Kemampuan sumber daya manusia bagi masyarakat Yogyakarta didukung dengan keberadaan lembaga pendidikan serta didukung perkembangan teknologi sehingga ada berbagai pilihan dalam usaha kaos sablon, baik skala kecil maupun besar.

Menurut Amstrong dan Kotler (2004), kemampuan usaha produk baru memerlukan kreativitas dan penguasaan teknologi baru. Menurut Dwijoko (2011), usaha kaos sablon memerlukan kreativitas dan model kekinian agar penampilannya menjadi menarik. Penampilan yang menarik memberikan kepuasan kepada konsumen dan diperlukan pengembangan desain. Menurut Yudiantoro (2004), konsep diri berupa nilai yang dimiliki oleh seseorang dengan tingkah laku yang dapat diarahkan untuk melindungi dan meningkatkan konsep diri.

Perilaku pengguna mengarahkan untuk meningkatkan konsep diri melalui sebagai konsumen suatu barang sebagai simbul. Masyarakat memperlihatkan dan menggunakan barang yang dibeli sebagai cermin/simbol seseorang dan bagi lainnya. Menurut Scifmen dan Kanuk (2004), persepsi ada dua jenis yaitu persepsi bawah sadar dan persepsi supra liminal.
Persepsi dibawah sadar adalah persepsi yang ditimbulkan oleh rangsangan dibawah level of conscious awareness sehingga seorang mengerjakan sesuatu tanpa disadari. Persepsi supra liminal merupakan persepsi yang ditimbulkan oleh rangsangan diatas level of conscious awareness sehingga seseorang mengerjakan sesuatu dengan penuh kesadaran.

\section{Kesesuaian Harga}

Menurut Anderson (2003), atribut dalam suatu produk perusahaan adalah harga produk. Saat ini para pengguna produk dalam menggunakan dana untuk pemeliharaannya sangat hati-hati dibandingkan pada masa lalu. Para pelanggan tidak lagi menjadi pihak yang terabaikan. Bahkan dalam beberapa usaha, konsumen menjadi penentu kelangsungan hidup perusahaan. Menurut Day (2004), penetapan sebuah harga merupakan penentu dalam penciptaan permintaan yang perlu diperhatikan oleh perusahaan sebagai peluang. Menurut Russel (2006), atribut yang melekat pada penetapan harga jual terdiri dari persaingan, situasi, kondisi, selera dan kelogisan.

Perkembangan selera dan keinginan konsumen cepat berubah sehingga berakibat produk kita menjadi usang dikarenakan perubahan lingkungan maupun faktor dalam perusahaan yang bersangkutan. Menurut Cooper (1997), konsumen menjadi penentu kelangsungan hidup perusahaan harga jangan tinggi sasaran keuntungan maksimal. Harga sebagai kekuatan dalam penggunaan uang sebagai nilai tukar bagi masyarakat untuk mendapatkan barang yang dibutuhkan dan diinginkannya. Menurut Matzler (2006), kepuasan harga mengacu pada kondisi yang dirasakan oleh konsumen berdasarkan perbandingan atau penilaian terhadap nilai yang diterima oleh konsumen dengan mengorbankan dalam kaitan harga. Bukan sesuatu yang aneh ketika perusahaan menutup usahanya karena tidak memiliki cukup pelanggan yang menguntungkan bagi kelangsungan hidupnya. 


\section{Kesukaan Model}

Menurut Dongoran (2001), konsumen memandang merek sebagai simbol prestis yang ditunjukkan oleh respon subjek sebesar 58,4\% yang menyatakan bahwa mereka merasa sebagai trend setter karena menggunakan merek yang dibelinya dan sebanyak $57,1 \%$ subjek setuju bahwa selebriti yang digunakan pada iklan komersial merek tersebut sesuai dengan citra yang ingin disampaikan. Menurut Stanton (2000), produk adalah sekumpulan atribut yang nyata (tangible) didalamnya sudah mencakup warna, harga, kemasan, model, merek dan pengecer, diterima oleh pembeli sebagai sesuatu yang memuaskan keinginannya. Menurut Cokajaya (2009), kegiatan pemasaran harga, model, citra tempat, distribusi, pelayanan dan promosi harga membentuk kesan kualitas yang signifikan dan positif.

Menurut Kotler (2003), kepuasan pelanggan sebagai hasil yang dirasakan oleh pembeli dari kinerja perusahaan yang memenuhi harapan mereka. Pelanggan puas bila harapan mereka terpenuhi dan senang bila harapannya terlebihi. Pelanggan yang puas akan setia lebih lama, kurang sensitif pada harga dan memberi komentar baik tentang merek yang dijual. Fungsi pengetahuan dapat membantu konsumen mengurangi ketidakpastian dan kebingungan dalam memilih informasi yang relevan dan tidak relevan terhadap kebutuhan. Pemahaman sikap konsumen merupakan hal yang sangat krusial. Pengembangan produk dapat dilakukan dengan terlebih dahulu.

Menurut Endah (2009), pengaruh karakteristik produk baru dan memori iklan media televisi berpengaruh terhadap keputusan konsumen secara positif dan signifikan. Menurut Marconi (1994), status atau lebih tepatnya persepsi akan status adalah hal yang dijual dari merekmerek berharga tinggi tersebut. Menurut Agung (2009), kepuasan harga bagi konsumen terhadap harga, mutu produk, model memberikan daya tarik yang positif. Menurut Pringle danThompson (2001), seiring waktu, model berubah menjadi suatu simbol bagi konsumen dimana model tertentu dianggap sebagai status, identifikasi diri, dan life style yang mewakili konsumen atau yang ingin dicapai oleh konsumen.

\section{Kualitas Barang}

Menurut Wijayanto (2009), kualitas barang yang diberikan bersama-sama dengan pelayanan akan mempengaruhi persepsi konsumen terhadap pelayanan yang dia terima. Semakin baik kualitas barang akan meningkatkan kepuasan konsumen terhadap pelayanan yang ia terima. Sebaliknya, barang yang kurang berkualitas akan merusak kepuasan konsumen secara keseluruhan. Selain itu konsumen biasanya memandang harga sebagai indikator dari kualitas suatu jasa, terutama jasa yang memiliki kondisi dimana kualitasnya sulit dideteksi sebelum jasa tersebut dikonsumsi. Hal tersebut berkaitan dengan kenyataan bahwa sifat jasa yang memiliki tingkat risiko yang cukup tinggi bila dibandingkan dengan produk barang. Dalam situasi dimana konsumen tidak dapat mengevaluasi barang dan jasa yang akan dibeli, maka ada kecenderungan bagi konsumen untuk menggunakan harga sebagai dasar menduga kualitas barang. Menurut Sianipar (2009), kualitas mempunyai pengaruh positif dan signifikan terhadap keinginan konsumen. Maka konsumen biasanya cenderung berasumsi harga yang tinggi mewakili kualitas yang tinggi atau dengan kata lain semakin mahal harga barang maka semakin bagus mutunya.

\section{Kepuasan Konsumen}

Menurut Aydin dan Ozer (2003), kemapanan dari pengaruh kepuasan, kepercayaan dalam meningkatkan loyalitas konsumen. Menurut Dahlstrom (2003), konsumen merasa puas dengan menggunakan produk dengan melakukan pembelian berulang kali serta memberitahukan kepada orang lain tentang 
pengalamannya menggunakan produk itu. Seseorang tidak merasa puas maka dia beralih ke tempat lain dengan berbagai alasan penolakan yang dianggap gagal olehnya dan menceritakan kepada orang lain. Menurut Lee (2010), kepuasan konsumen tercermin dari perilaku pembelian ulang dan merekomendasikan kepada pihak lain secara positif. Menurut Antonio, Minguzzi (2002), semakin tinggi tingkat kualitas layanan yang diberikan, konsumen akan menjadi loyal berkunjung ke restoran.

Berdasarkan hasil penelitian-penelitian tersebut, kualitas pelayanan terdiri dari enak dipakai, harga, kemasan menarik, corak kaos sablon, ukuran standar, variasi model, kualitas, sopan, kemampuan pelayanan karyawan, kebersihan, empati kepada pengunjung, dan lokasi meningkatkan kepuasan.

Berpijak pada tinjauan pustaka dan riset sebelumnya, maka dapat dirumuskan hipotesis sebagai berikut:

$\mathrm{H}_{1}$ : Kesesuaian harga berpengaruh positif terhadap kepuasan konsumen.

$\mathrm{H}_{2}$ : Kesukaan model berpengaruh positif terhadap kepuasan konsumen.

\section{METODE PENELITIAN}

\section{Populasi dan Sampel}

Populasi berupa sejumlah masyarakat yang dapat mewakili dalam suatu analisis yang memiliki ciri yang dapat diduga. Populasi dalam penelitian ini adalah mereka yang membeli, pernah membeli, singgah serta berlangganan di kawasan Malioboro yang menjual kaos sablon yang berasal dari kotamadya Yogyakarta maupun dari luar. Penelitian ini menggunakan ukuran sampel 100 orang sebagai responden melalui cara purposive sampling method. Pengukuran variabel dilakukan dengan lima skala Likert.

\section{Metode Analisis Data}

Analisis data mendasarkan pada hasil tanggapan dan pendapat konsumen terhadap harga, kualitas merek dan model. Pendekatan analisis data menggunakan model regresi berganda. Model regresi linear berganda untuk variabel bebas terhadap variabel terikat mempunyai formula sebagai berikut:

$$
\mathbf{Y}=\mathbf{a}+\mathbf{b}_{1} \mathbf{X}_{1}+\mathbf{b}_{2} \mathbf{X}_{2}+\mathbf{e}_{\mathbf{i}}
$$

Dimana $\mathrm{Y}$ adalah keputusan konsumen untuk membeli kaos sablon di kawasan Malioboro Yogyakarta, $\mathrm{X}_{1}$ adalah harga pembelian kaos sablon, $\mathrm{X}_{2}$ adalah model kaos sablon, a adalah konstanta, dan $\mathrm{b}_{1}, \mathrm{~b}_{2}, \mathrm{~b}_{3}, \mathrm{~b}_{4}$ adalah koefisien korelasi.

Pengujian hipotesis berdasarkan pada uji t. Tujuan uji ini adalah untuk menguji ada tidaknya pengaruh kesesuaian harga dan model terhadap kepuasan konsumen untuk membeli kaos sablon di kawasan Malioboro Yogyakarta. Sementara itu untuk membandingkan kekuatan pengaruh disetiap variabel independen terhadap variabel dependen indikator yang digunakan adalah $\beta$ (koefisien beta) variabel independen. Variabel independen disebutkan sebagai yang mendominasi pengaruh variabel independen lainnya terhadap variabel dependen apabila memiliki koefisien beta terbesar. Pengujian model regresi berdasarkan pada distribusi $F$ dengan membandingkan $\mathrm{F}_{\text {hitung }}$ dengan $\mathrm{F}$ tabel Pengujian regresi berganda dilakukan dengan bantuan program SPSS 13.0 for windows.

\section{HASIL PENELITIAN DAN PEMBAHASAN}

\section{Karakteristik Subyek Penelitian}

Berdasarkan hasil pengumpulan data, penelitian yang dilakukan di kawasan Malioboro Yogyakarta yang menjual kaos sablon dilakukan olah data 100 responden. Karakteristik subjek penelitian meliputi jenis kelamin, umur, pendidikan, pekerjaan serta penghasilan. 
Tabel 1

Karakteristik Responden Berdasarkan Jenis Kelamin

\begin{tabular}{cccc}
\hline No & Keterangan & Jumlah & Persentase \\
\hline 1 & Perempuan & 67 & 67 \\
2 & Laki-Laki & 33 & 33 \\
\hline & Jumlah & 100 & 100 \\
\hline
\end{tabular}

Sumber: data diolah

Karakteristik berdasarkan jenis kelamin para responden yang terkumpul menurut tabel 1 memberikan informasi bahwa kebanyakan jumlah perempun yang membeli kaos sablon dominan dengan angka 67 hal demikian mereka puas dengan penampilan kaos sablon yang dirasa memberikan gambaran yang up to date dengan mengenakannya kain dan kaos sablon berada di kawasan Malioboro Yogyakarta.

Karakteristik umur responden disajikan pada tabel 2. Menurut tabel 2 memberikan informasi bahwa responden berdasarkan umur memberi tanggapan terhadap kain dan kaos sablon yang diperoleh di Malioboro Yogyakarta berdasarkan usia 16 tahun sampai 30 tahun sebagai pembeli potensial dengan persentase 67 dan usia 15 tahun kebawah dengan persentase 17 diikuti usia diatas 30 tahun sebanyak 16 persen maka secara positif dan signifikan potensi pembeli kain dan kaos sablon berusia 16 tahun sampai 30 tahun. Memperhatikan paparan di tabel 2 menunjukkan bahwa para responden yang membeli kaos sablon di kawasan Malioboro Yogyakarta adalah golongan muda. Berpijak pada kondisi demikian bahwa para pembeli kaos sablon untuk dipakai dan untuk buah tangan para pembeli cenderung mengikuti tren atau mode dan mencari penampilan yang beda dalam berpenampilan sehari-hari dimasyarakat. Para pembeli merasa percaya diri dengan penampilan dan model yang terpampang di kaos sablon menjadikan diri semakin bangga.

Tabel 2

\begin{tabular}{cccc}
\multicolumn{4}{c}{ Karakteristik Responden Berdasarkan Usia } \\
\hline No & Keterangan & Jumlah & Persentase \\
\hline 1 & $£ 15$ tahun & 17 & 17 \\
2 & $16-20$ tahun & 24 & 24 \\
3 & $21-25$ tahun & 22 & 22 \\
4 & $26-30$ tahun & 21 & 21 \\
5 & $>30$ tahun & 16 & 16 \\
\hline \multicolumn{5}{c}{ Jumlah } & 100 & 100 \\
\hline
\end{tabular}

Sumber: data diolah

Tabel 3

Karakteristik Responden Berdasarkan Pendidikan

\begin{tabular}{clcc}
\hline No & Keterangan & Jumlah & Persentase \\
\hline 1 & SD & 15 & 15 \\
2 & SLTP & 27 & 27 \\
3 & SLTA & 31 & 31 \\
4 & PT & 27 & 27 \\
\hline & Jumlah & 100 & 100 \\
\hline
\end{tabular}

Sumber: data diolah

Karakteristik responden sebanyak 100 orang di tabel 3 memberikan informasi bahwa responden berdasarkan latar belakang pendidikan yang beragam dengan pendidikan Sekolah Lanjutan Tingkat Atas sebanyak 31 persen diikuti berpendidikan tinggi 27 persen serta Sekolah Lanjutan Tingkat Pertama sebanyak 27 persen dan yang terakhir berpendidikan Sekolah Dasar sebanyak 15 persen berarti para responden sangat respek terhadap kain dan kaos sablon bermacam corak dengan nuansa edukatif. Kenyamanan responden didasarkan pada pelaku usaha kaos sablon memiliki latar belakang pendidikan dan budaya tercermin pada kota Yogyakarta sebagai kota pendidikan dan budaya berskala nasional sampai internasional. 
Tabel 4

Karakteristik Responden Berdasarkan Pekerjaan

\begin{tabular}{clcc}
\hline No & \multicolumn{1}{c}{ Keterangan } & Jumlah & Persentase \\
\hline 1 & Pelajar/Mahasiswa & 32 & 32 \\
2 & PNS & 21 & 21 \\
3 & Pegawai swasta & 24 & 24 \\
4 & IRT & 16 & 16 \\
5 & Wiraswasta & 7 & 7 \\
\hline \multicolumn{2}{c}{ Jumlah } & 100 & 100 \\
\hline
\end{tabular}

Sumber: data diolah

Berpijak di tabel 4 memberikan informasi bahwa 100 responden yang berkunjung dikawasan Malioboro Yogyakarta memiliki latar belakang berprofesi paling dominan pelajar/mahasiswa sebanyak 32 persen diikuti pegawai swasta 24 persen dan diikuti Pegawai Negeri Sipil 21 persen dan potensi terakhir wiraswasta 7 persen. Mereka membeli kaos sablon di kawasan Malioboro Yogyakarta dikarenakan memiliki wawasan dan pergaulan yang luas serta menganggap kaos sablon dapat mewakili penampilan mereka yang santai dan nyaman untuk kuliah dan bergaul serta mudah dalam menggunakannya.

Tabel 5

Komposisi Responden Menurut Pendapatan per Bulan

\begin{tabular}{lcc}
\hline \multicolumn{1}{c}{ Pendapatan } & Jumlah & Prosentase (\%) \\
\hline$\leq$ Rp. 2.000.000,- & 16 & $16 \%$ \\
Rp. 2.000.000,- s.d Rp. 4.000.000,- & 42 & $42 \%$ \\
Rp. 4.000.000,- s.d Rp. 6.000.000,- & 31 & $31 \%$ \\
$\geq$ Rp. 6.000.000,- & 11 & $11 \%$ \\
$\quad$ Jumlah & 100 & $100 \%$ \\
\hline
\end{tabular}

Sumber: data diolah

Tabel 4 menjelaskan karakteristik penghasilan responden per bulan, berpenghasilan Rp 2.000.000,00 s.d Rp 4.000.000,00 sebesar $42 \%$, Rp 4.000.000,00 s.d Rp 6.000.000,00 sebesar $31 \%$ responden berpenghasilan $\leq \mathrm{Rp}$ $2.000 .000,00$ sebesar $16 \%$ dan responden berpenghasilan $\geq \operatorname{Rp~} 6.000 .000,00$ sebesar $11 \%$ maka pembeli potensial untuk kaos sablon adalah mereka yang memiliki pendapatan per bulan Rp 2.000.000,00 ke atas sebagai pasar potensial berarti pasar di kawasan Malioboro adalah menengah kebawah untuk itu penjual kaos sablon perlu menyesuaikan kemampuan pembeli.

Untuk menguji hipotesis, peneliti menggunakan alat sebagai model persamaan regresi berganda. Hasil dari pengolahan analisis regresi berganda yang telah dilakukan didapatkan koefisien $0,045 \mathrm{X}_{1}$ dan nilai koefisien $0,058 \mathrm{X}_{2}$ berarti kedua koefisien bernilai posiotif. Dari hasil analisa dapat disimpulkan bahwa koefisien harga dengan diberi simbol $\mathrm{X}_{1}$ dan koefisien model dengan simbol $\mathrm{X}_{2}$ memiliki arah positif terhadap kepuasan para pembeli kaos di kawasan Malioboro Yogyakarta dengan simbol (Y). Terjadi perubahan kepuasan terhadap para pembeli kaos sablon searah dengan terjadi perubahan pada harga yang ditanggung pembeli dan model yang tersedia di kawasan Malioboro Yogyakarta. Nilai yang diperoleh dari koefisien regresi untuk harga pada simbol $\mathrm{X}_{1}$ sebesar 0,045 berarti ada perubahan yang positif per satuan maka terjadi perubahan kepuasan konsumen dengan simbol Y secara signifikan naik dengan nilai sebesar 0,045 . Demikian pula dengan penurunan untuk harga dengan simbol $\mathrm{X}_{1}$ per satuan maka kepuasan konsumen dengan simbol $\mathrm{Y}$ secara signifikan turun sebesar 0,045dengan beranggapan kesukaan model dengan simbol $\mathrm{X}_{2}$ tetap.

Nilai yang diperoleh dari koefisien regresi untuk kesukaan model pada simbol $\mathrm{X}_{2}$ sebesar 0,058 berarti ada perubahan yang positif per satuan maka terjadi perubahan kepuasan konsumen dengan simbol Y secara signifikan naik dengan nilai sebesar 0,058 . Demikian pula dengan penurunan untuk kesukaan model dengan simbol $\mathrm{X}_{2}$ per satuan maka kepuasan konsumen dengan simbol Y secara signifikan turun sebesar 0,058 dengan beranggapan kesesuaian harga dengan simbol $\mathrm{X}_{1}$ tetap. 
Dari hasil pengujian model regresi dengan melalui hasil perhitungan uji $\mathrm{F}$ diperoleh hasil $\mathrm{F}$ hitung sebesar 54,224 $>$ F Tabel $=2,45$. Hasil regresi itu mengindikasikan kepuasan pembeli kaos sablon dipengaruhi oleh kesesuaian harga dan kesukaan model. Maka dapat disimpulkan kesesuaian harga $\left(\mathrm{X}_{1}\right)$ dan kesukaan model $\left(\mathrm{X}_{2}\right)$ secara serempak mempunyai pengaruh yang positif dan signifikan terhadap kepuasan konsumen (Y) hipotesis diterima. Sedangkan untuk hal yang lain model ini memperhatikan hasil analisis koefisien determinasi $\left(\mathrm{R}^{2}\right)$ adalah 0,695 berarti $69,5 \%$ terjadi kepuasan para konsumen yang dapat dijelaskan oleh kesesuaian harga $\left(\mathrm{X}_{1}\right)$ dan kesukaan model $\left(\mathrm{X}_{2}\right)$ dan sedangkan 30,5\% dipengaruhi oleh faktor lain yang tidak diteliti.

\section{Kesesuaian Harga dan Kepuasan Konsumen Membeli Kaos Sablon}

Hasil uji $t$ dengan pengujian yang dilakukan dengan dua sisi menggunakan tingkat signifikansi sebesar $\alpha=5 \%$ dan df $=\mathrm{n}-2=98$, maka didapatkan $\mathrm{t}$ tabel sebesar $\left({ }_{1} /{ }_{2} \alpha=0,025\right.$; $\mathrm{df}=98)=1,960$ dan hasil $\mathrm{T}_{\text {hitung }}$ 2,774 maka dapat dikatakan bahwa kesesuaian harga menunjukkan secara parsial memiliki pengaruh yang positif dan signifikan terhadap kepuasan konsumen.

\section{Kesesuaian Model dan Kepuasan Konsumen terhadap Kaos Sablon}

Hasil uji $t$ dengan pengujian yang dilakukan dengan dua sisi menggunakan tingkat signifikansi sebesar $\alpha=5 \%$ dan df $=\mathrm{n}-2=98$, maka didapatkan $\mathrm{t}$ tabel sebesar $\left(1 /{ }_{2} \alpha=0,025\right.$; $\mathrm{df}=98)=1,960$ dan hasil $\mathrm{T}_{\text {hitung }} 10,883$. Oleh karena hasil uji t statistik (t-hitung) lebih besar dari nilai kritis $(10,883>1,960)$. Dari hasil ini menunjukkan bahwa kesukaan model secara parsial memiliki pengaruh yang positif dan signifikan terhadap kepuasan para pembeli kaos di kawasan Malioboro Yogyakarta. Hasil ini mendukung hipotesis $\mathrm{H}_{2}$.
Berdasarkan pada hasil regresi linear berganda untuk kesesuaian harga kaos sablon dengan simbol $\left(\mathrm{X}_{1}\right)$ diperoleh beta 0,045 dan kesesuaian model dengan simbol $\left(\mathrm{X}_{2}\right)$ diperoleh beta 0,9 berarti kesesuaian harga dengan simbol $\left(\mathrm{X}_{1}\right)<$ dari kesukaan model dengan simbol $\left(\mathrm{X}_{2}\right)$. Berdasar pada perbandingan koefisien beta dapat dikatakan bahwa faktor yang dominan untuk penentuan transaksi adalah kesukaan model untuk mendapatkan kepuasan konsumen. Kesimpulan dari hasil penelitian uji regresi linear berganda dengan melalui uji $\mathrm{F}$ dan uji t dapat menampilkan untuk faktor kesesuaian harga dan faktor kesukaan model memiliki nilai yang berpengaruh positif terhadap kepuasan konsumen. Pada hasil uji $\mathrm{F}$ menampilkan bahwa kesesuaian harga dan faktor kesukaan model secara serempak memiliki pengaruh yang positif serta signifikan terhadap kepuasan konsumen. Hasil analisis untuk uji $t$ dapat disimpulkan bahwa hasil dari kesesuaian harga dan kesukaan pada model secara parsial memiliki nilai yang berpengaruh positif terhadap kepuasan konsumen. Faktor yang dominan terdapat pada kesukaan model untuk mempengaruhi kepuasan konsumen.

\section{KESIMPULAN DAN SARAN}

Berdasarkan hasil penelitian dan pembahasan, maka dapat disimpulkan beberapa hal penting. Pertama kesesuaian harga mempengaruhi secara positif terhadap kepuasan konsumen hal demikian berdasarkan hasil analisis regresi berganda dan hasil perhitungan uji $\mathrm{F}$ serta hasil uji t memperoleh nilai positif. Kedua kesukaan model memiliki faktor yang positif dalam mempengaruhi kepuasan konsumen didukung berdasarkan hasil analisis regresi berganda dan hasil perhitungan uji $\mathrm{F}$ serta hasil uji t memperoleh nilai positif. Ketiga kesukaan model memiliki faktor yang dominan dalam mencapai kepuasan konsumen hal demikian didapat dari hasil analisis koefisien beta sebesar 0,9 dari hasil regresi 
linear berganda. Keempat kaos sablon digemari oleh semua kalangan terutama anak muda. Penelitian ini memiliki keterbatasan. Untuk itu ada beberapa saran untuk penelitian selanjutnya. Adapun saran untuk penelitian selanjutnya yaitu pertama, penelitian ini hanya terbatas pada kesesuaian harga dan kesukaan model sehingga bisa saja faktor yang dipilih tidak cukup relevan dengan fenomena yang ada. Peneliti selanjutnya dapat menambah faktor kualitas serta ketersedian barang lainnya yang dapat mempengaruhi kepuasan konsumen dalam membeli kaos sablon. Kedua, penelitian ini menggunakan program SPSS 13.0 for windows dengan sampel 100 responden perlu dicoba dengan Amos agar lebih detail dengan responden diatas 100. Ketiga perlu ditingkatkan kemampuan sumber daya manusia untuk mengembangkan ide-ide yang up to date agar kaos sablon semakin diinginkan oleh para pengunjung di kawasan Malioboro Yogyakarta.

\section{DAFTAR PUSTAKA}

Agung, Anak Agung Gde. 2009. Pendekatan Sentra Kluster dalam Mengembangkan UKM. Jakarta: Kementrian Koperasi dan UKM.

Amstrong, Gary, dan Philip Kotler. 1994. "Targeting Prospects for a New Product", Jurnal of Advertising Research, 17-26.

Anderson, James C. 2003. "Dimensions of Price Satisfaction A Study in The Retail Banking Industry", International Journal of Bank Marketing, 1 (6), 93117.

Antonio, Minguzzi. 2002."Success Factors in SMEs Internationalization Processes: An Italian Investigation", Journal of Small Business Management, 40 (2), 144-153.

Aydin, S, dan Ozer, G. 2003. "How Brand to Loyalty in the Turkish Mobile Phone Market", Journal of Targeting,
Measurement and Analysis Marketing, 1 (6), 93-117.

Cokajaya. 2009. Pengaruh Harga, Kualitas, Jenis dan Kemasan terhadap Keputusan Konsumen dalam Melakukan Pembelian Cindramata, Skripsi. Fakultas Ekonomi Universitas Muhamadiyah Surakarta.

Cooper, Robert G. 1997." The New Prod System: The Industry Experience", Journal of Product Innovation Management, 2 (1), 62-74.

Dahlstrom, Robert. 2003. "Investigation to New Product Success", Journal of Marketing Research, 107-119.

Day, George S. 2004. "Do Focus Group Have a Future", Marketing, June 6.

Dongoran, J. 2001. "Loyalitas Model dan Merek pada Produk Tertentu", Jurnal Ekonomi dan Bisnis, September, 7 (2), 206-232.

Dwijoko. 2011. 'Pengaruh Minat Masyarakat Terhadap Atribut Kaos Sablon", Jurnal Akuntansi dan Manajemen, 12 (2), 274.

Endah. 2009. Pengaruh Karakteristik Produk Baru dan Memori Iklan Media Televisi terhadap Keputusan Konsumen Membeli Pakaian di Kelurahan Makam Haji Surakarta. Skripsi Fakultas Ekonomi Universitas Muhamadiyah Surakarta.

Florida. 2002. "The Economic Geography of Talent", Annals of the Assosiation American Geographers, 92 (4), 743755.

Kotler, Philip. 2003. Marketing Management. $11^{\text {th }}$ Edition. New Jersey: Prentince International Hall Inc.

Lee, Ming-Shing, Huey-Der Hsiao, dan Ming-Fen Yang. 2010. "The Study of Relationships Among Experiential Marketing, Service Quality, Customer Satisfaction and Customer Loyalty", The International Journal of Organizational Innovation.

Marconi. 1994. ’Kepuasan Konsumen Berasal dari Loyalitas", Majalah Tempo, 39. 
Matzler, K, Wurtele, A, dan Renzl, B. 2006. "Satisfaction, Repurchase Intent, and Repurchase Behavior: Investigating The Moderating Effect of Customer Characteristics", Journal of Marketing Research, 3 (3), 102-114.

Pringle dan Thompson. 2001. Consumer Behavior. New Jersey: Prentice International Hall Inc.

Russel. 2006. "The Marketing Revolution", Journal of Marketing, 1 (36-42).

Scifmen dan Kanuk. 2004. Consumer Behavior. Seventh Edition. New York: Mc Graw Hill.

Sianipar, Lidia Meidiana. 2009. Pengaruh Kepuasan Konsumen terhadap Loyalitas Merek Hypermart Plasa Medan. Skripsi. Program S1 Fakultas Ekonomi Universitas Sumatra Utara Medan.

Simatupang. 2008. Perkembangan Industri Kreatif, diakses dari bandung creative city blog. files.wordpress.com/2008/03/ perkembangan_ind_kreatif 3 November 2008.
Stanton, William J. 2000. Multiattribute Decisions in Marketing. USA: Dryden Press.

Supantono, Widihardjo, dan Achmad Haldani. 2006. Identifikasi Unsur-Unsur Simbolik Pada Usaha Kreatifitas Masyarakat Yogyakarta 1995-2015.

Sutisna. 2002. Perilaku Konsumen Konsep dan Implikasi Untuk strategi dan Penelitian Pemasaran. Cetakan kedua. Jakarta: Preda Media.

Wendri, Rusli. 2012. "Pengaruh Pelayanan terhadap Loyalitas Melalui Mediasi Kepuasan dan Kepercayaan", Efektif Jurnal Bisnis dan Ekonomi, 3 (2) Desember, 139-148.

Wijayanto, Catur. 2009. Pengaruh Harga, Kualitas, Jenis dan Kemasan terhadap Keputusan Konsumen dalam Melakukan Pembelian Pakaian di Pasar Klewer Solo. Skripsi. Universitas Muhamadiyah Surakarta

.Yudiantoro, Danang. 2004. “Analisis Pengaruh Kesesuaian Diri terhadap Kesukaan Merk dan Kepuasan”, Jurnal Telaah Bisnis, Desember. 